\title{
Coordinated Control of Parallel DR-HVDC and MMC-HVDC Systems for Offshore Wind Energy Transmission
}

\author{
Rui Li, Lujie Yu, Lie Xu, Senior Member, IEEE and Grain Philip Adam, Member, IEEE
}

\begin{abstract}
Parallel operation of diode rectifier based highvoltage direct current (DR-HVDC) and modular multilevel converter (MMC) based HVDC (MMC-HVDC) for transmitting offshore wind energy is investigated in this paper. An enhanced active power control scheme of the offshore MMC station is proposed to improve the power flow distribution between the MMC-HVDC and DR-HVDC links which are both connected to the offshore wind farm AC network. By regulating the offshore voltage, all the wind powers are transmitted via the DR-HVDC link in low wind conditions while the offshore MMC power is controlled around zero to reduce transmission losses, considering the efficiency superiority of DR-HVDC over its MMC counterpart. When the DR-HVDC is out of service, wind energy is transferred via the MMC-HVDC and the wind turbine generated power is automatically limited by slightly increasing the offshore AC voltage to avoid potential MMC-HVDC overload. A power curtailment control is also proposed which slightly increases the DC voltage of the DR-HVDC to enable autonomous reduction of the generated wind power so as to avoid DR-HVDC overload during MMC-HVDC outage. The proposed coordinated control only uses local measurements and, without the need for communication, can seamlessly handle transitions including various faults. The proposed scheme enables fault ride-through operation and provides a high efficient solution with flexible operation for integrating large offshore wind farms. Simulation results confirm the proposed control strategy.
\end{abstract}

Index Terms - coordinated control, diode rectifier based HVDC (DR-HVDC), fault ride-through, modular multilevel converter (MMC) based HVDC (MMC-HVDC), offshore wind farms, parallel operation, power flow distribution.

\section{INTRODUCTION}

Due to improved controllability and superior system performances, high-voltage direct current (HVDC) transmission systems based on modular multilevel converters (MMCs) are being used for integrating long distance offshore wind farms (OWFs) [1-3]. Many studies have been conducted on the control and operation of the offshore MMC station. One common approach is to use the offshore MMC to form the offshore AC grid with fixed frequency control [1,2]. The $d q$ reference frame is directly obtained by integrating the desired frequency (e.g. $50 \mathrm{~Hz}$ ), whereas the $q$-axis output voltage

The work is supported in part by the European Union's Horizon 2020 research and innovation program under grant agreement No 691714.

R. Li, L. Xu, and G. P. Adam are with the Department of Electronic and Electrical Engineering, University of Strathclyde, Glasgow, G1 1XW, UK (email: rui.li@strath.ac.uk, lie.xu@strath.ac.uk, grain.adam@strath.ac.uk).

L. Yu is with the School of Electrical and Information Engineering, Tianjin University, Tianjin, 300072, China (e-mail: lujie_yu@outlook.com). reference of the MMC is directly set at zero and the $d$-axis voltage is actively regulated to control the offshore voltage magnitude. However, as the control scheme only contains voltage control loop with no current controllability, the offshore MMC stations could suffer overcurrents in the event of offshore AC faults.

To avoid overcurrents during faults, decoupled current controllers are introduced in [4-6]. The proposed current controllers are bypassed during normal operation but are activated once the currents are out of the predefined threshold to switch the offshore MMC to current control mode so as to limit the output currents. After fault clearance, the offshore MMC is switched back to the voltage control mode. However, the switching between voltage and current control modes can potentially lead to high transient currents [4-6]. To tackle this issue, the cascaded control structure with outer voltage loop and inner current loop is used in $[3,7,8]$ to control both offshore voltage and current while avoiding control mode switching. However, the interaction between the voltage and the transmitted power was not investigated.

The diode rectifier (DR) based HVDC (DR-HVDC) systems have recently received notable interests for integrating large offshore wind farms [9-11]. By replacing the MMC offshore station with diode rectifier, the volume and weight of the offshore platform can be significantly reduced while in the meantime increasing the transmission capacity $[9,10]$. In addition, it also leads to substantial reduction in the transmission losses and the total cost, e.g. $20 \%$ and $30 \%$ respective reductions as quoted in $[9,10]$.

A voltage and frequency control of the offshore wind turbines (WTs) connected with DR-HVDC system is presented in [12], which proves that such solution is technically feasible in steady states and transients. In [13] and [14], various fault cases, including DC faults, symmetrical onshore and offshore AC faults, are tested and the fault ride-through capability of DR-HVDC is validated. However, each WT requires the measured voltage at the point of common connection (PCC), necessitating the need for high-speed communication. A distributed phase locked loop (PLL) based control is proposed in [15] to provide offshore AC voltage and frequency control, and share reactive power among WTs without communication. With the developed controller, the system can ride-through onshore and offshore AC faults. A fast fault current injection control is further proposed in [16] to regulate the WT currents during fault transients and enable overcurrent and differential protection.

Due to MMC's superior controllability and the low losses 
This paper is a post-print of a paper submitted to and accepted for publication in IEEE Journal of Emerging and Selected Topics in Power Electronics and is subject to Institution of Electrical and Electronic Engineering Copyright. The copy of record is available at IEEE Xplore Digital Library.

and compactness of the diode rectifier, both MMC-HVDC and DR-HVDC can be used for offshore wind energy transmission and this paper aims to combines these advantages together. By interconnecting the offshore MMC and DR stations on the AC side, the wind energy can still be transmitted through the healthy HVDC link if the other HVDC links is out of service. This paper investigates such parallel operations of DR-HVDC and MMC-HVDC considering normal operation and various faults. The main contributions of this paper are:

- An enhanced power control scheme of the offshore MMC station is proposed to improve the active power flow distribution of the parallel system. By regulating the offshore AC voltage, all the wind power is transmitted via DR-HVDC link in low wind conditions while the offshore MMC power is actively controlled at around zero to reduce transmission losses, considering the efficiency superiority of a DR station over its MMC counterpart.

- An additional power limit control of the offshore MMC station is proposed to limit the power transmitted through the MMC-HVDC link when the DR-HVDC is out of service. By slightly increasing the offshore AC voltage, the WT generated power is automatically reduced to avoid overloading of the MMC-HVDC link.

- The characteristics of the offshore power-voltage curve is derived to design the control of the parallel system, considering various operation modes of the offshore MMC station, i.e. active power control mode, voltage control mode, and power limiting mode.

- A power curtailment control of the DR-HVDC is proposed which slightly increases its DC link voltage by controlling the onshore MMC to enable autonomous curtailment of the generated offshore wind power so as to avoid DR-HVDC overload during MMC-HVDC outage.

The paper is organized as follows. The layout of the parallel system is described in Section II. In Section III, the offshore power-voltage characteristics and control requirements of WT converters connected with DR-HVDC system are addressed. The coordinated control strategy is proposed in Section IV. In Section V, the proposed coordinated control of the parallel system is assessed and finally, Section VI draws conclusions.

\section{PARALLEL OPERATION OF DR-HVDC AND MMC-HVDC}

The layout of the parallel connected DR-HVDC and MMCHVDC systems for offshore wind power transmission is illustrated in Fig. 1, where OWFs 1 and 2 contain 100 and 150 WTs each rated at $8 \mathrm{MW}$ respectively. The wind energies generated by OWFs 1 and 2 are originally transmitted to onshore through the MMC-HVDC and DR-HVDC links, respectively. An additional AC cable $C a b_{1}$ is used to interconnect the offshore MMC and DR stations on their AC sides to enable parallel operation. The half-bridge (HB) submodule (SM) based MMCs are adopted for the offshore and onshore MMC stations [17]. The onshore stations $\mathrm{MMC}_{2}$ and $\mathrm{MMC}_{3}$ regulate their respective $\mathrm{DC}$ voltages. The $\mathrm{DR}$ station is composed of a 12-pulse DR bridge and filters are connected on its AC side for reactive power compensation and harmonic suppression $[9,18]$. The detailed parameters of the modelled HVDC stations are listed in Table I.

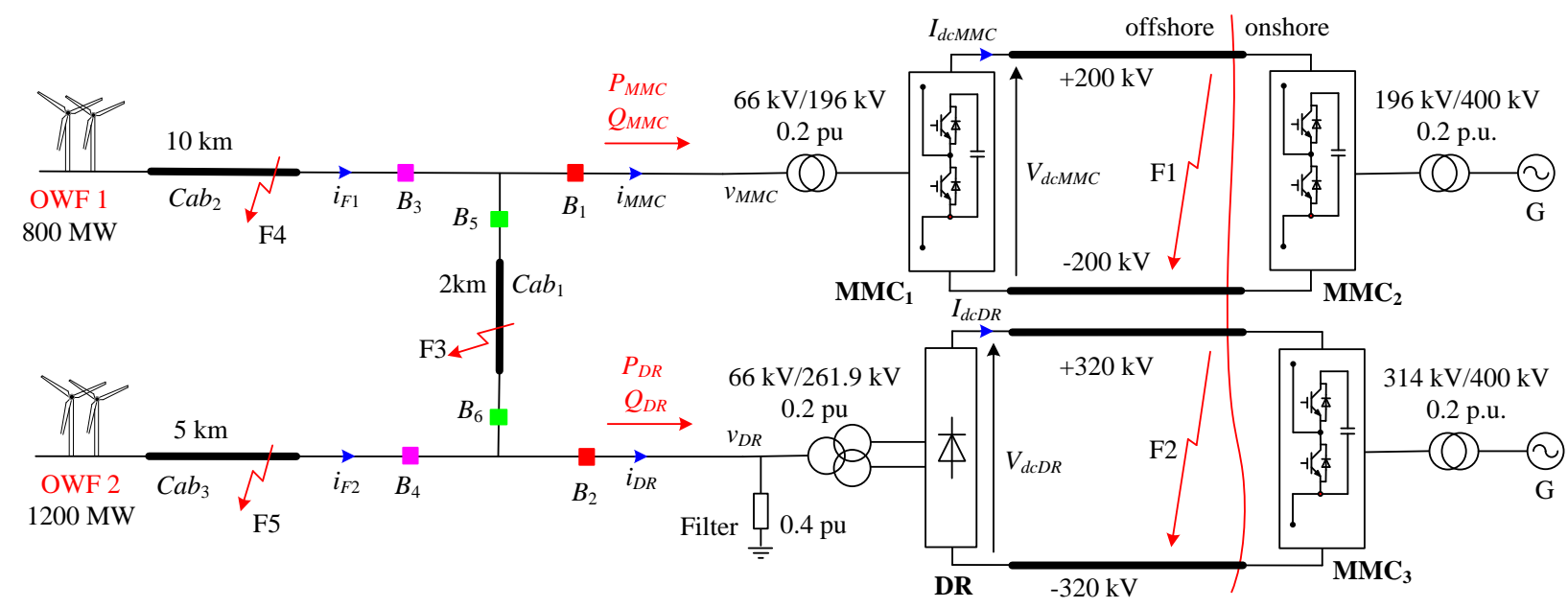

Fig. 1. Layout of the parallel connected DR-HVDC and MMC-HVDC systems for offshore wind power transmission.

The presented parallel operation, where two HVDC links are connected in parallel on AC sides, is similar with the "hub-andspoke" scheme proposed by ABB [19] and provides a viable option for offshore wind power transmission, considering the following features:

- When a new wind power plant is developed in area next to an existing offshore wind farm which is connected to onshore through MMC-HVDC link [19-21], DR-HVDC link with its offshore AC side connected to the existing offshore wind farm and MMC station in which the DR- and MMC-HVDC links operate in parallel, potentially provides a promising solution to reduce losses, volume and capital cost, while increase redundancy and availability. The newly built DR-HVDC link can reduce the cost by $30 \%$ compared to its MMC counterpart, as presented in $[9,10]$. - The newly built DR-HVDC link can have different DC voltage to that of the existing MMC-HVDC link, and thus the presented scheme enables parallel operation of DR- and MMC-HVDC links with different DC voltages.

- With such parallel arrangements, when one HVDC link is out of service due to scheduled system maintenance, converter failure, or DC faults etc., the generated wind power can still be transmitted via the other HVDC link, enhancing the system reliability and availability [21], as will be demonstrated in Sections V-B and V-C.

- A challenge for DR-HVDC technology is the start-up of the 
This paper is a post-print of a paper submitted to and accepted for publication in IEEE Journal of Emerging and Selected Topics in Power Electronics and is subject to Institution of Electrical and Electronic Engineering Copyright. The copy of record is available at IEEE Xplore Digital Library.

offshore AC grid due to the unidirectional characteristics of DR station. By connecting MMC-HVDC and DR-HVDC on their AC sides, the offshore MMC station is capable of energizing the offshore grid and wind turbines. It can also actively compensate reactive power and suppress harmonics generated by the DR station if required, so as to reduce $\mathrm{AC}$ filter switching during the variation of wind speed [22].

- The scheme with two HVDC links can simultaneously supply offshore wind power to asynchronous onshore AC grids $[23,24]$. This improves system operability during disturbance on one of the onshore AC networks. In addition, the power distribution between the two separate onshore $\mathrm{AC}$ grids can be actively controlled and optimized, e.g. for minimizing losses in the onshore AC grids [25].

- It makes easier for staged construction of the HVDC project by different developers [20,21].

TABLE I

Nominal Parameters of the Modeled HVDC Stations

\begin{tabular}{|c|c|c|}
\hline & PARAMETER & Nominal Value \\
\hline \multirow{6}{*}{$\begin{array}{l}\mathrm{MMC}_{1} \& \\
\mathrm{MMC}_{2}\end{array}$} & DC-link voltage & $\pm 200 \mathrm{kV}$ \\
\hline & Power rating & $800 \mathrm{MW}$ \\
\hline & SM number per arm & 160 \\
\hline & SM capacitor voltage & $2.5 \mathrm{kV}$ \\
\hline & SM capacitance & $9.8 \mathrm{mF}$ \\
\hline & Arm inductance & $0.1 \mathrm{pu}$ \\
\hline \multirow{6}{*}{$\mathrm{MMC}_{3}$} & DC-link voltage & $\pm 320 \mathrm{kV}$ \\
\hline & Power rating & $1200 \mathrm{MW}$ \\
\hline & SM number per arm & 256 \\
\hline & SM capacitor voltage & $2.5 \mathrm{kV}$ \\
\hline & SM capacitance & $7.7 \mathrm{mF}$ \\
\hline & Arm inductance & $0.1 \mathrm{pu}$ \\
\hline \multirow{4}{*}{$\begin{array}{l}\text { 12-pulse } \\
\text { DR bridge }\end{array}$} & DC-link voltage & $\pm 320 \mathrm{kV}$ \\
\hline & Power rating & $1200 \mathrm{MW}$ \\
\hline & Number of diode connected in-series & 100 \\
\hline & Rated DC voltage of each diode & $3.2 \mathrm{kV}$ \\
\hline
\end{tabular}

The system arrangement in Fig. 1 can have the following four operation modes during normal and various fault conditions for improved efficiency, reliability and availability:

Mode 1: Parallel operation. $C a b_{1}$ is connected, and the generated wind energies of OWFs 1 and 2 can be actively shared between the offshore MMC and DR stations.

Mode 2: MMC-HVDC operation. The DR station is isolated from the AC side via circuit breaker $B_{2}$ and the power generated by both OWFs are transmitted through the MMC-HVDC link. This can be the case when the DRHVDC link is out of service, e.g. scheduled system maintenance, converter failure, or DC fault (F2), resulting in the disconnection of $B_{2}$ to isolate the DRHVDC system from the offshore AC network.

Mode 3: DR-HVDC operation. The offshore MMC is isolated from the $\mathrm{AC}$ side via circuit breaker $B_{1}$ and the generated wind power by both wind farms are transmitted through the DR-HVDC link. This can happen during MMC-HVDC outage, e.g. scheduled system maintenance, converter failure, or DC fault (F1), causing the opening of breaker $B_{1}$ to isolate the MMC-HVDC system from the offshore AC network.

Mode 4: Independent operation. The interconnection cable $C a b_{1}$ is disconnected, e.g. during $\mathrm{AC}$ fault $\mathrm{F} 3$, which leads to the opening of breakers $B_{5}$ and $B_{6}$. The generated power of OWFs 1 and 2 are then transmitted through the MMC-HVDC and DR-HVDC links, respectively.

\section{ChARACTERISTICS OF THE DR-HVDC SYSTEMS}

\section{A. Offshore P-V Characteristics}

Fig. 2 shows the equivalent circuit of the DR-HVDC link in diode conduction mode. During normal operation, the onshore station $\mathrm{MMC}_{3}$ controls its DC terminal voltage at the rated value $V_{d c 0}$ and is thus represented in the equivalent circuit by a voltage source $V_{d c 0}$. The total DC voltage $V_{d c D R}$ produced by the DR is expresses by the phase voltage amplitude of the offshore grid $v_{d}[15]$ :

$$
V_{d c D R}=\frac{6}{\pi}\left(\sqrt{3} n v_{d}-X_{T} I_{d c D R}\right)=\frac{6}{\pi}\left(\sqrt{3} n v_{d}-X_{T} \frac{P_{D R}}{V_{d c D R}}\right)
$$

where $n$ is the transformer ratio, $X_{T}$ is the leakage reactance of the DR transformer, and $I_{d c D R}$ and $P_{D R}$ are the DC current and the transmitted power at the DC terminals of the DR respectively. From (1), the DC voltage produced by the DR is thus derived as

$$
V_{d c D R}=\frac{3 \sqrt{3} n v_{d}+\sqrt{27 n^{2} v_{d}^{2}-6 \pi X_{T} P_{D R}}}{\pi} .
$$

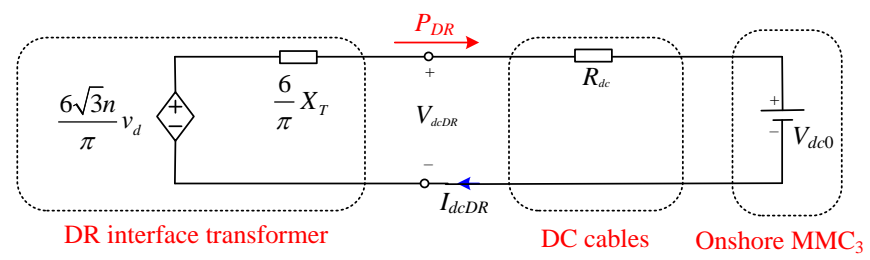

Fig. 2. Equivalent circuit of the DR-HVDC link in diode conduction mode.

From the equivalent circuit shown in Fig. 2, there are

$$
V_{d c D R}=V_{d c 0}+R_{d c} I_{d c D R}=V_{d c 0}+R_{d c} \frac{P_{D R}}{V_{d c D R}}
$$

where $R_{d c}$ is the equivalent resistance of the DC cables. From (3), $V_{d c D R}$ is expressed as

$$
V_{d c D R}=0.5 V_{d c 0}+\sqrt{0.25 V_{d c 0}^{2}+R_{d c} P_{D R}} .
$$

From (2) and (4), the transformer ratio $n$ is governed by 
This paper is a post-print of a paper submitted to and accepted for publication in IEEE Journal of Emerging and Selected Topics in Power Electronics and is subject to Institution of Electrical and Electronic Engineering Copyright. The copy of record is available at IEEE Xplore Digital Library.

$$
n=\frac{2 \pi\left(V_{d c 0}+\sqrt{{V_{d c 0}}^{2}+4 R_{d c} P_{D R 0}}\right)}{24 \sqrt{3} V_{d 0}}+\frac{\sqrt{2} X_{T} P_{D R 0}}{\sqrt{3} V_{d 0}\left(V_{d c 0}+\sqrt{V_{d c 0}{ }^{2}+4 R_{d c} P_{D R 0}}\right)}
$$

where $P_{D R 0}$ is the rated power of the DR-HVDC link and $V_{d 0}$ is the rated phase voltage amplitude of the offshore grid. Setting the DR interface transformer ratio $n$ according to (5), the DR station transmits the rated power of $P_{D R 0}$ when the offshore voltage is at the rated value $V_{d 0}$.

\section{B. Control Requirements of WTs Connected with DR-HVDC Systems}

In the event of offshore MMC station outage, the system operates on DR-HVDC mode and the offshore AC voltage is controlled by WT front-end converters (FECs) as presented in Fig. 3 [15]. As seen, the reference of the offshore voltage amplitude $v_{d W T}^{*}$ is set by the active power controller to regulate the generated active power $P_{W T}$, and when $v_{d W T}^{*}$ is lower than $0.9 \mathrm{pu}$, the DR is reverse blocked and the WT generated power is zero. To increase $P_{W T}$, the offshore voltage amplitude $v_{d W T}^{*}$ is actively increased by the active power controller. The offshore voltage is largely maintained in the range of $0.9 \sim 1 \mathrm{pu}$ with the variation of active power from zero to the rated value, due to the low resistance of DC cable and constant DC voltage at the onshore MMC terminal. The reference of the offshore $q$ axis voltage $v_{q W T}^{*}$ is set by the reactive power controller to ensure reactive power sharing among WT converters [15]. The $d$ - and $q$-axis voltage controllers set the $d$ - and $q$-axis current references of $i_{d W T}^{*}$ and $i_{q W T}^{*}$, respectively. The active power reference $P_{W T}^{*}$ of WTs is set according to the operation of the WTs, e.g. maximum power point tracking (MPPT) control [26, 27].

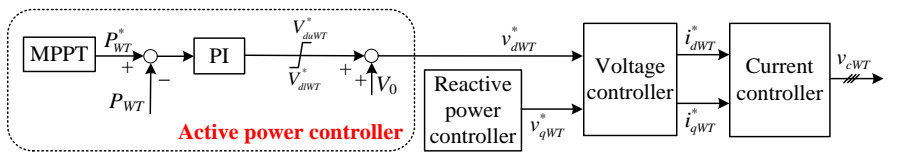

Fig. 3. Control scheme of offshore WT front-end converters.

\section{ENHANCED POWER Flow CONTROL OF THE PARALLEL SYSTEM WITH DR-HVDC AND MMC-HVDC}

Despite the aforementioned advantages, one particular challenge for the parallel system is the precise control of power distribution between the DR-HVDC and MMC-HVDC links. If the offshore MMC station controlled the offshore voltage at a constant value as in conventional approaches [28], the power transmitted through the parallel connected DR-HVDC would be fixed. To actively control the power flow of the DR-HVDC link, additional power controllers are proposed for the offshore MMC station to slightly adjust the offshore voltage so as to precisely share active power between the two HVDC links.

Similar to the WT FECs, the offshore MMC station also has active power controller, reactive power controller, voltage controller, and current controller, as illustrated in Fig. 4. With the developed control strategy, the offshore MMC shares the responsibility for offshore grid regulation with the WTs, which significantly improves the offshore AC voltage controllability of the parallel system.

In the proposed control scheme, the offshore MMC station operates on either power control mode or voltage control mode to ensure power sharing between the parallel connected MMC and DR stations to reduce transmission losses.

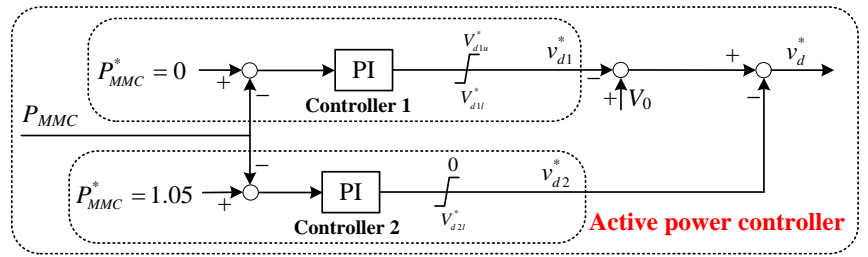

(a)

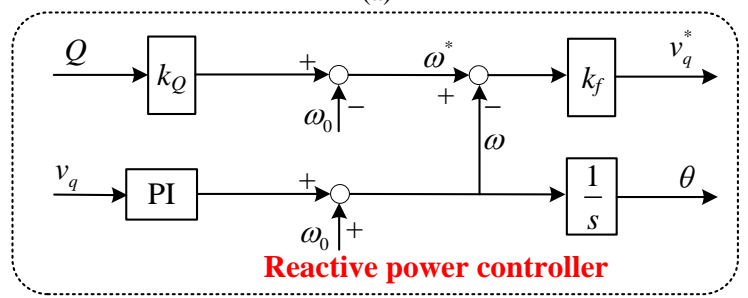

(b)

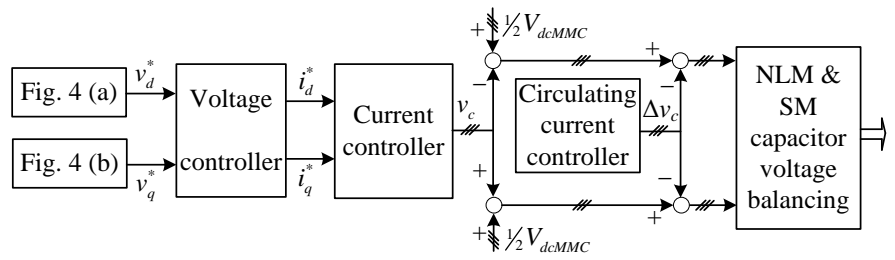

(c)

Fig. 4. Proposed control of offshore MMC station: (a) active power controller, (b) reactive power controller, and (c) complete control diagram.

\section{A. Active Power Control Mode}

In low wind conditions, where the total power generated by OWFs 1 and 2 is lower than the rated power of the DR station, the active power Controller 1 with reference $P_{M M C}^{*}$ set at zero is activated while Controller 2 saturates, as shown in Fig. 4 (a). The offshore MMC station operates on active power control mode and the power flow of the MMC-HVDC link is controlled around zero by regulating the offshore AC voltage magnitude which indeed affects the power transmitted by the DR-HVDC system. Thus, all the wind power is transmitted to onshore via the DR-HVDC link to minimize transmission power losses, considering the relatively higher efficiency of the DR station compared to its MMC counterpart.

Considering the DC voltage is maintained at $V_{d c 0}$ at the onshore DC terminal, the offshore AC voltage threshold $V_{t h}$ when DR station starts to conduct can be derived from Fig. 2 as:

$$
V_{t h}=\frac{\pi V_{d c 0}}{6 \sqrt{3} n} .
$$

When the WT generated power is zero, the offshore grid voltage needs to be lower than $V_{t h}$ to avoid the conduction of DR and possible circulating power between the DR-HVDC and MMC-HVDC links.

\section{1) System start-up:}

As shown in Fig. 4 (a), during start-up of the offshore network, the Controller 2 saturates at the upper limit 0 and does not involve in the voltage regulation. The active power Controller 1 with reference $P_{M M C}^{*}$ of 0 regulates the offshore voltage as

$$
v_{d}^{*}=v_{d}=V_{0}-v_{d 1}^{*}-v_{d 2}^{*}=V_{0}-v_{d 1}^{*} \approx 0.85 V_{d 0}
$$

where $V_{0}$ is the start-up voltage and is set at $0.85 V_{d 0} ; v_{d 1}^{*}$ and 
This paper is a post-print of a paper submitted to and accepted for publication in IEEE Journal of Emerging and Selected Topics in Power Electronics and is subject to Institution of Electrical and Electronic Engineering Copyright. The copy of record is available at IEEE Xplore Digital Library.

$v_{d 2}^{*}$ are the output of Controller 1 and 2, respectively. As $V_{0}$ is lower than the threshold voltage $V_{t h}$ defined by (6), DR is reverse blocked. The total transmitted power transmission between the offshore and onshore grids is thus zero.

2) DR conducting stage:

With the increase of the wind speed, the WTs start to generate power and the offshore grid voltage is increased from $0.85 V_{d 0}$ by the WT control strategy illustrated in Fig. 3. Once the offshore network voltage is greater than the threshold voltage $V_{t h}$, the diode rectifiers conduct to transmit power and the DC voltage of the diode station $V_{d c D R}$ is thus derived as:

$$
V_{d c D R}=\frac{\sqrt{3} n v_{d}+\frac{X_{T} V_{d c 0}}{R_{d c}}}{\frac{\pi}{6}+\frac{X_{T}}{R_{d c}}}=6 \frac{\sqrt{3} n R_{d c} v_{d}+X_{T} V_{d c 0}}{\pi R_{d c}+6 X_{T}} .
$$

When the DR station transmits rated power $P_{D R 0}$, the offshore voltage is regulated at the rated $V_{d 0}$ :

$$
v_{d}\left(P_{D R 0}\right)=V_{d 0} \text {. }
$$

From (6), (8), and (9) as well as the parameters as illustrated in Fig. 1, it can be derived that the threshold voltage $V_{t h}$ is around $0.9 \mathrm{pu}$, i.e. $0.9 V_{d 0}$. With the variation of active power from zero to the rated value, the offshore voltage can be maintained within the safety operating region and is largely in the range of $0.9 \sim 1 \mathrm{pu}$, due to the low resistance of DC cable and constant DC voltage at the onshore MMC terminal.

At low wind power generation, Controller 1 with $P_{M M C}^{*}=0$ actively regulates the voltage reference $v_{d}^{*}$ to ensure all the wind power is transmitted to onshore through the DR-HVDC link and the active power $P_{M M C}$ flowing through MMC is zero. The power-voltage profiles of the parallel connected MMCHVDC and DR-HVDC links are thus depicted as (10), which is also illustrated in Fig. 5 (a) and (b), respectively.

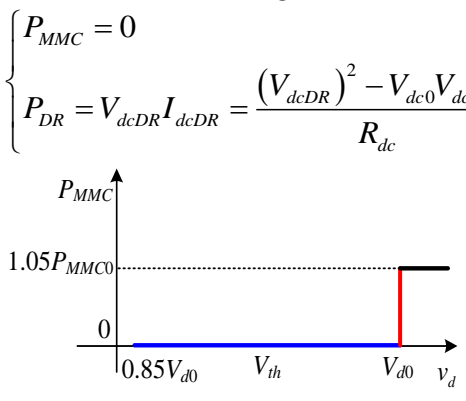

(a)

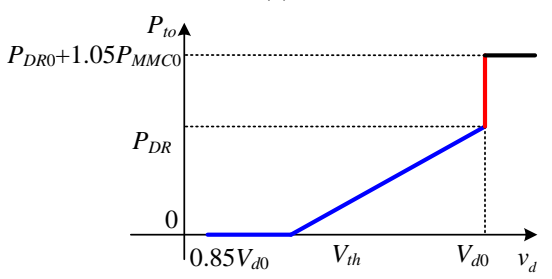

(c)

Fig. 5. Offshore power-voltage characteristics for the parallel operated MMCHVDC and DR-HVDC links: (a) MMC-HVDC, (b) DR-HVDC, and (c) parallel system.

\section{B. Voltage Control Mode}

When the generated wind power exceeds the capacity of the DR-HVDC system, the transmitted power of DR station reaches the rated value $P_{D R O}$ and the surplus wind energy needs to be transmitted through the MMC-HVDC link. As $P_{M M C}^{*}$ is set at zero, the active power Controller 1 of the offshore MMC saturates and outputs the lower limit $V_{d 1 l}^{*}$ which is set at $0.15 V_{d 0}$. Thus the MMC station operates on voltage control mode and regulates the offshore voltage at rated value:

$$
v_{d}^{*}=v_{d}=V_{0}-v_{d 1}^{*}-v_{d 2}^{*}=V_{0}-V_{d 1 l}^{*}=V_{d 0} .
$$

As seen, both the active power controllers saturate and the offshore MMC autonomously and seamlessly transfers from power control mode to voltage control mode without the need for communication or operation mode detection. The DR station operates with rated power $P_{D R 0}$ while the extra generated power is transmitted to onshore via the MMC-HVDC link:

$$
\left\{\begin{array}{l}
P_{M M C}=P_{F 1}+P_{F 2}-P_{D R 0}, \quad v_{d}=V_{d 0} \\
P_{D R}=P_{D R 0}
\end{array}\right.
$$

where $P_{F 1}$ and $P_{F 2}$ are the active power generated by OWFs 1 and 2, respectively. From (10) and (12), the relationship between the offshore voltage and the total transmitted power $P_{t o}$ can be expressed by (13) and is also illustrated in Fig. 5 (c). $P_{t o}=P_{M M C}+P_{D R}=$

$\begin{cases}0, & v_{d} \leq V_{t h} \\ \left(6 \frac{\sqrt{3} n R_{d c} v_{d}+X_{T} V_{d c 0}}{\pi R_{d c}^{3 / 2}+6 X_{T} \sqrt{R_{d c}}}\right)^{2}-\frac{6}{R_{d c}} \frac{\sqrt{3} n R_{d c} V_{d c 0} v_{d}+X_{T} V_{d c 0}{ }^{2}}{\pi R_{d c}+6 X_{T}}, & V_{t h}<v_{d}<V_{d 0} . \\ P_{F 1}+P_{F 2}, & v_{d}=V_{d 0}\end{cases}$

\section{Active Power Limiting Control in Mode 2}

In MMC-HVDC operation (Mode 2), the DR station is isolated from the offshore network and the power from both OWFs 1 and 2 is transmitted to the onshore through the MMCHVDC link, which can be higher than MMC's transmission capability. The active power Controller 2 as shown in Fig. 4 (a) is thus proposed to automatically reduce the generated wind power and avoid overloading of the MMC-HVD link.

As shown in Fig. 4 (a), with the power reference $P_{M M C}^{*}$ set at $1.05 \mathrm{pu}$, the output of Controller 2 of the offshore $\mathrm{MMC}_{1}$ saturates at the upper limit of zero during normal operation and does not involve in the offshore voltage regulation. Once the MMC power is over $1.05 \mathrm{pu}$, Controller 2 activates and slightly increases the offshore AC voltage. Consequently, the active power controllers of the WTs saturate and the WTs operate on voltage control mode. Without communication, the power generated by WTs is automatically reduced and the potential overloading of the MMC-HVDC system is avoided, as shown in Fig. 5 (b). To alleviate the WT DC overvoltage and avoid over-speed of WT generators, pitch control is adopted to reduce the captured wind energy $[29,30]$. DC chopper can also be used to dissipate the generated surplus wind power [31, 32].

The offshore MMC regulates the offshore network voltage to enable enhanced power sharing between the DR-HVDC and MMC-HVDC links. The coordinated control between the offshore MMC and WTs relies on the local measurements without any communication requirement. The proposed control scheme can seamlessly handle transitions between active power control and voltage control modes as well as various faults for the parallel system, as will be demonstrated in Section V. 
This paper is a post-print of a paper submitted to and accepted for publication in IEEE Journal of Emerging and Selected Topics in Power Electronics and is subject to Institution of Electrical and Electronic Engineering Copyright. The copy of record is available at IEEE Xplore Digital Library.

\section{Power Curtailment Control by Onshore Station $M M C_{3}$ in Mode 3}

In DR-HVDC operation (Mode 3), the offshore MMC station is isolated from the offshore grid and the wind powers generated by both OWFs 1 and 2 are transmitted via the DRHVDC link. The maximum power transmission capability of the system is thus reduced to $0.6 \mathrm{pu}$ for the considered configuration. To avoid overloading of the DR-HVDC link, a power curtailment control for the onshore $\mathrm{MMC}_{3}$ is presented in Fig. 6, where an additional DC current loop is adopted to increase the DC voltage $V_{d c}$ once DC overcurrents occur. As shown, if the DC current $I_{d c}$ is lower than the pre-set maximum DC current order $I_{d c}^{*}$ (e.g. $1.1 \mathrm{pu}$ ), the input of the PI controller is limited at zero by the dead zone block such that the DC voltage order $V_{d c}^{*}$ for the onshore $\mathrm{MMC}_{3}$ of the DR-HVDC is at the rated value. If $I_{d c}$ exceeds the maximum value, the PI controller generates a positive output to slightly increase the DC voltage of the DR-HVDC so the power transmitted from the DR and WTs is automatically limited. In the meantime, the WTs will limit the generated power through pitch control [29, 30].

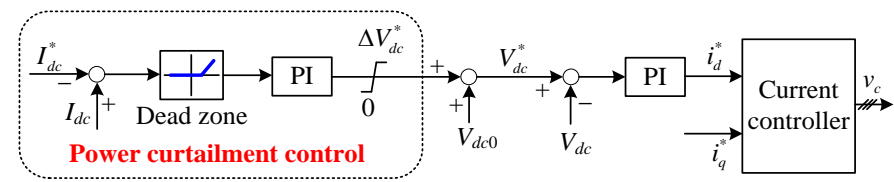

Fig. 6. Power curtailment control of onshore station $\mathrm{MMC}_{3}$ in DR-HVDC link.

\section{E. Reactive Power Sharing Control}

\section{1) Control design}

In addition to AC side filters, the offshore MMC and WT converters can compensate the reactive power consumed by the DR station. To share the required reactive power among the offshore MMC station and WTs, reactive power frequency $(Q$ $f$ ) droop control as shown in Fig. 4 (b) is adopted to dynamically set the frequency reference $\omega^{*}$ as $[10,12,33,34]$ :

$$
\omega^{*}=\omega_{0}+k_{Q} Q
$$

where $\omega_{0}$ is the rated frequency of the offshore network, $k_{Q}$ is the droop gain, and $Q$ is the reactive power. The per-unit value of the reactive power of each WT and offshore $M_{1}$ is measured and fed to the frequency loop for reactive power sharing (proportional to their own capacity). The offshore network frequency $\omega$ is derived by PLL and fed to the frequency loop, which sets the $q$-axis voltage reference $v_{q}^{*}$ to regulate the offshore AC frequency [15].

\section{2) Operating principle for reactive power sharing}

To illustrate the operating principle of the reactive power sharing control, a single-phase representation of the system is shown in Fig. 7 (a), where $V_{M M C}$ is the amplitude of the voltage at the MMC AC terminal whose phase angle is taken as the reference (zero), $V_{i}$ and $\theta_{i}(i=1,2, \ldots, h)$ are the respective output voltage amplitude and phase angle of the FEC of the $i$ th WT, and $X_{i}$ is the equivalent reactance between the $i$ th WT and the MMC AC terminal.

Assuming the reactive power $Q_{1}$ of WT 1 is greater than the average reactive power of other WTs and the offshore MMC station (in per unit terms) and is required to be reduced, the frequency reference $\omega_{1}{ }^{*}$ of WT 1 is higher than that of other WTs due to the reactive power frequency $(Q-f)$ droop control depicted by (14). Consequently, the phase difference $\theta_{1}$ between $V_{1}$ and $V_{M M C}$ (phase angle of $V_{M M C}$ is used as the reference) increases. The voltage amplitude $V_{M M C}$ at the MMC AC terminal is determined by the transmitted active power $P_{d c D R}$ as depicted by (15) and remains unchanged:

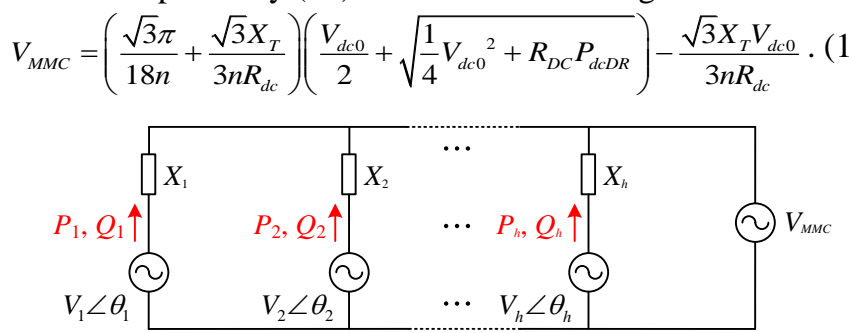

(a)

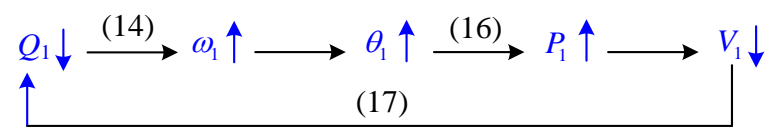

(b)

Fig. 7. Reactive power sharing illustration: (a) single-phase diagram of the offshore network and (b) relationship among control variables.

The active power output $P_{1}$ of WT 1 tends to increase due to the increased angle $\theta_{1}$ as governed by (16). In the meantime, the increase of $P_{1}$ causes the active power controller to reduce the output voltage $V_{1}$ to ensure $P_{1}$ unchanged. The reactive power $Q_{1}$, as expressed as (17), is thus reduced, yielding shared reactive power among the offshore WTs and MMC station. The relationships of the different variables are graphically shown in Fig. 7 (b) for ease of understanding.

$$
\begin{gathered}
P_{1}=\frac{V_{0} V_{1} \sin \theta_{1}}{X_{1}} \\
Q_{1}=\frac{V_{1}\left(V_{1}-V_{0} \cos \theta_{1}\right)}{X_{1}}
\end{gathered}
$$

\section{SiMULATION}

The proposed control scheme is assessed using the model shown in Fig. 1 in PSCAD X4, where OWFs 1 and 2 are represented by 4 and 6 lumped converters each rated at $200 \mathrm{MW}$ respectively. Thus, a total of $10 \mathrm{WT}$ converters are considered in this paper and small-signal modelling method is used for tuning WT control parameters, where the eigenvalues of the linearized small-signal model are calculated and suitable parameters of the converter controllers are obtained to ensure dynamic stability [5, 35-37]. The generator-side converter is simplified as a DC voltage source of $1100 \mathrm{~V}[12,14,38]$ while the aggregated FECs and the DR station are represented by detailed switching models. The MMC stations are represented by detailed submodule-based switching function model [39]. The combined system time delay introduced by sampling, calculation, and modulation is $63 \mu \mathrm{s}, 63 \mu \mathrm{s}, 36 \mu \mathrm{s}$, and $750 \mu \mathrm{s}$ for $\mathrm{MMC}_{1}, \mathrm{MMC}_{2}, \mathrm{MMC}_{3}$, and WT converters, respectively $[40,41]$.

\section{A. Power Flow Regulation in Parallel Operation (Mode 1)}

Fig. 8 presents simulation results with the proposed power flow control. Initially, the output power of the WTs is zero as shown in Fig. 8 (c), and the offshore voltage is controlled around $0.85 \mathrm{pu}$, as seen in Fig. 8 (a). At $t=1 \mathrm{~s}$, the wind power ramps up to $0.6 \mathrm{pu}$ within $0.2 \mathrm{~s}$ by increasing the voltage as observed in Fig. 8 (d), and the offshore AC voltage is gradually 
This paper is a post-print of a paper submitted to and accepted for publication in IEEE Journal of Emerging and Selected Topics in Power Electronics and is subject to Institution of Electrical and Electronic Engineering Copyright. The copy of record is available at IEEE Xplore Digital Library.

increased to around the rated value. With the proposed power flow controller, the DR-HVDC has the priority to transmit wind power over the MMC-HVDC to reduce transmission losses. The first $1.2 \mathrm{GW}$ wind power is all transmitted via DR-HVDC link while the offshore MMC operates on power control mode with its active power regulated at zero, as shown in Fig. 8 (b) and (c).

The wind power is further increased to the rated value during the period of $2 \mathrm{~s}$ to $2.2 \mathrm{~s}$. The active power Controller 1 in Fig. 4 saturates and sets the voltage reference at $1 \mathrm{pu}$, as shown in Fig. 8 (a). $M M_{1}$ then operates on voltage control mode and starts to transmit the excessive power which exceeds the power capability of the DR station, Fig. 8 (b). The base power of the DR and MMC stations are set at 1200 MW and 800 MW respectively and thus their power both reach 1 pu when the WTs generate the rated power. As shown in Fig. 8 (f), reactive power is automatically shared between the offshore MMC and WT converters. The three-phase currents of WTs in Fig. 8 (e) are in agreement with the generated active and reactive power as displayed in Fig. 8 (c) and (f).

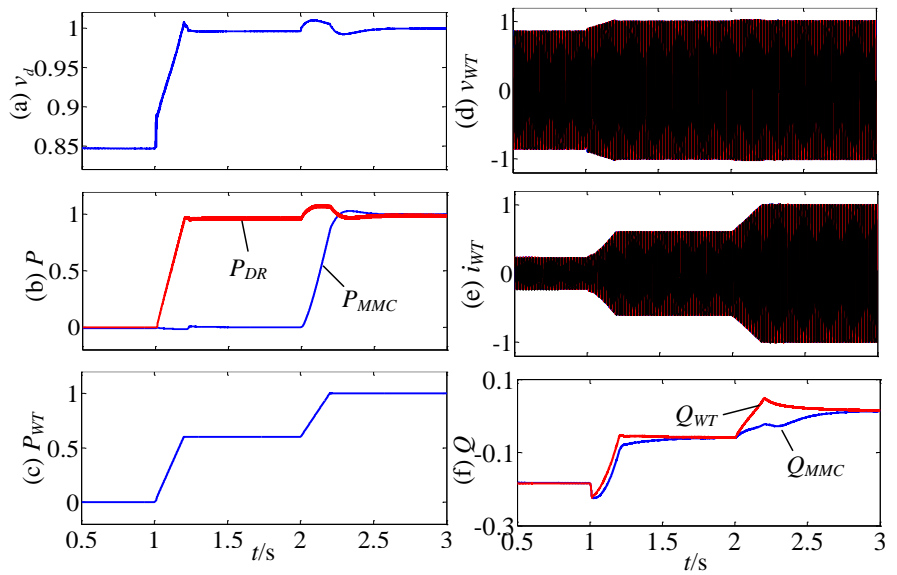

Fig. 8. Power flow regulation of the parallel system: (a) offshore AC voltage magnitude, (b) active power of $\mathrm{MMC}_{1}$ and DR, (c) WT active power, (d) WT three-phase voltages, (e) WT three-phase currents, and (f) reactive power of WT and offshore $\mathrm{MMC}_{1}$.

As can be seen, during variation of generated wind power, the offshore MMC automatically changes operation modes without communication. The transition of the operation modes is smooth and the parallel system does not experience severe disturbance. The proposed control strategy achieves the desired power flow sharing between the DR-HVDC and MMC-HVDC links, leading to reduced transmission losses.

\section{B. DC Fault on MMC-HVDC Link (Mode 3)}

In this scenario, a pole-to-pole DC fault is applied at the middle MMC-HVDC cable at $t=0.9 \mathrm{~s}$.

As shown in Fig. 9 (c), the DC voltage of the MMC-HVDC collapses following the fault and the offshore and onshore MMC stations are quickly blocked at $t=0.901 \mathrm{~s}[42,43]$. Due to the DC fault, the offshore AC voltage (measured at WT AC terminals) also drops and the offshore frequency experiences disturbance, as displayed in Fig. 9 (h) and (i). The WT converters thus provide fault currents to support the $\mathrm{AC}$ voltage and enable fault detection, which largely flow through the antiparallel diodes of the MMC and feed the fault, as seen from Fig. 9 (j). The AC currents of the offshore MMC is increased from 1 pu to around $2.8 \mathrm{pu}$ after the fault occurrence. AC circuit breaker $B_{1}$ is thus opened according to overcurrent protection to isolate the DC fault (assuming at $t=1.04 \mathrm{~s}$ for illustration) from the offshore wind farm AC network. The offshore voltage gradually restores due to AC voltage control of the WT converters as can be seen in Fig. 9 (i). Both OWFs 1 and 2 transfer power via DR-HVDC link and once the DR-HVDC current is over the threshold of $1.1 \mathrm{pu}$, the proposed power curtailment control is activated on the onshore $\mathrm{MMC}_{3}$ to slightly increase the DC voltage of the DR-HVDC from 1 pu to 1.07 pu, as seen from Fig. 9 (a) and (b), respectively. This leads to the saturation of WTs' active power controller as shown in Fig. 9 (f), which sets the WT voltage reference $v_{d W T}^{*}$ at the upper limit (1.05 pu in this paper). The WTs thus operate on voltage control mode and limit the voltage at 1.05 pu, see Fig. 9 (g), and consequently, the active power of WTs is decreased from $1 \mathrm{pu}$ to $0.7 \mathrm{pu}$, as seen from Fig. 9 (f). The proposed method considers the unique characteristics of DR-HVDC system that its transmitted wind power is sensitive to the DC voltage and slight DC voltage increase can significantly reduce the generated wind power. Considering such characteristics and insulation requirements, the upper limit $\Delta V_{d c}^{*}$ of the proposed power curtailment controller in Fig. 6 is set at 0.1 pu. The active power of the DR-HVDC link is thus effectively limited to 1.2 pu, as displayed in Fig. 9 (e).

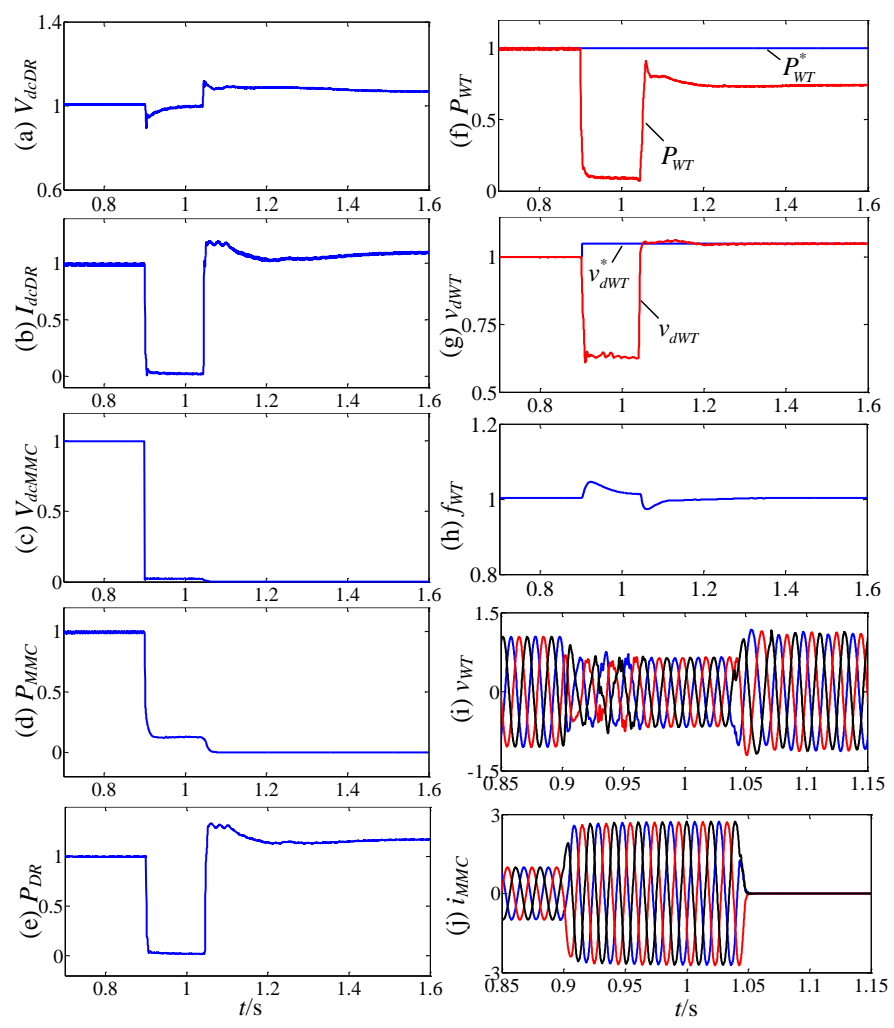

Fig. 9. Waveforms of DR-HVDC operation during MMC-HVDC fault F1: (a) DR-HVDC voltage, (b) DR-HVDC current, (c) MMC-HVDC voltage, (d) $\mathrm{MMC}_{1}$ active power, (e) DR active power, (f) WT active power, (g) WT $d$-axis voltage, (h) offshore frequency measured at WT terminals, (i) WT AC voltages, and (j) $\mathrm{MMC}_{1} \mathrm{AC}$ currents.

Due to the parallel connection, faults on one HVDC link also result in active power drop of the other link. However, after fault isolation by opening the corresponding AC circuit breaker, power transmission by the healthy HVDC link quickly restores and the generated active power of both wind farms can be 
This paper is a post-print of a paper submitted to and accepted for publication in IEEE Journal of Emerging and Selected Topics in Power Electronics and is subject to Institution of Electrical and Electronic Engineering Copyright. The copy of record is available at IEEE Xplore Digital Library.

transmitted to onshore networks.

Without communication, the generated wind power is automatically reduced after MMC-HVDC faults and the potential DC overcurrents of the DR-HVDC link are thus avoided. To avoid over-speed of the WT generators, the WTs need to limit the power through pitch control $[29,30]$.

\section{DC Fault on DR-HVDC Link (Mode 2)}

A DR-HVDC fault F2 is applied at the middle of the DC cable at $t=0.9 \mathrm{~s}$ and the DR-HVDC voltage collapses following the fault, as can be seen in Fig. 10 (a). To restore the offshore $\mathrm{AC}$ voltages, the voltage controller of the offshore MMC actively increases the $q$-axis current and reduces the $d$-axis current, Fig. 10 (f). The active power of the offshore MMC is thus reduced to around zero during the fault, as displayed in Fig. $10(\mathrm{~g})$. Different to the fault case considered at the DC side of the MMC-HVDC described earlier, where only WT converters provide fault currents, the offshore MMC station also outputs fault currents of $1.1 \mathrm{pu}$ to enable fault detection and support the offshore voltage, which still remains around 0.6 pu during the fault, as shown in Fig. 10 (d), (e), and (f). The fault currents provided by MMC and WT converters (Fig. 10 (e) and (1)) flow through the DR station and feed the fault. The DR-HVDC currents and breaker $B_{2}$ currents thus increase from $1 \mathrm{pu}$ to around 2.6 pu, as shown in Fig. 10 (b) and (c), and breaker $B_{2}$ opens at $t=1.04 \mathrm{~s}$ to isolate the DC fault from the offshore AC network using overcurrent protection. The current of $2.6 \mathrm{pu}$ during the DC fault is well within the typical overcurrent capability of diodes and does not expose the DR station to overcurrent damage.

After fault isolation, the wind energy generated by OWFs 1 and 2 are transmitted to onshore through the MMC-HVDC link and once the transmitted power is over the threshold of $1.05 \mathrm{pu}$, the proposed Controller 2 is activated to slightly increase the offshore voltage, as shown in Fig. 10 (d). As a result, the WTs' active power control loops saturate and set the voltage reference at the upper limit of 1.05 pu as shown in Fig. 10 (j) and (k), as the reference voltage of the offshore MMC has priority and is higher than that of WTs. The WTs operate on voltage control mode while the WT active power $P_{W T}$ does not follow the reference $P_{W T}^{*}$ and is automatically reduced to $0.42 \mathrm{pu}$ (see Fig. $10(\mathrm{j}))$, due to the higher offshore AC voltage set by the offshore MMC station. The transmitted power through the MMC-HVDC link is thus limited to $1.05 \mathrm{pu}$ as shown in Fig. $10(\mathrm{~g})$, and the potential overcurrent issue in MMC-HVDC operation is avoided. The WTs exhibit different behaviors as conventional ones due to the adopted intermediate voltage control loop as shown in Fig. 3, which actively limits the generated power, as detailed in [15].

The back-calculation anti-windup method is used in this paper to prevent integration wind-up in PI controllers when the actuators are saturated. Once the MMC power is over the threshold of 1.05 pu after the isolation of DR-HVDC faults, the output of Controller 2 immediately starts to decrease from its upper limit of zero due to the anti-windup function, where a feedback loop is adopted to discharge the Controller 2's internal integrator when the controller hits the specified saturation limit of zero and enters nonlinear operation. This is confirmed by Fig. 10 (e), which demonstrates that the AC currents of the offshore MMC are effectively limited to around the rated value by the proposed control and normal operation is quickly restored after fault isolation.

During the entire simulation scenario, the reactive power are shared among the offshore MMC and WT converters and the offshore frequency is largely controlled around the rated value of $50 \mathrm{~Hz}$, as shown in Fig. 10 (h) and (i), respectively.

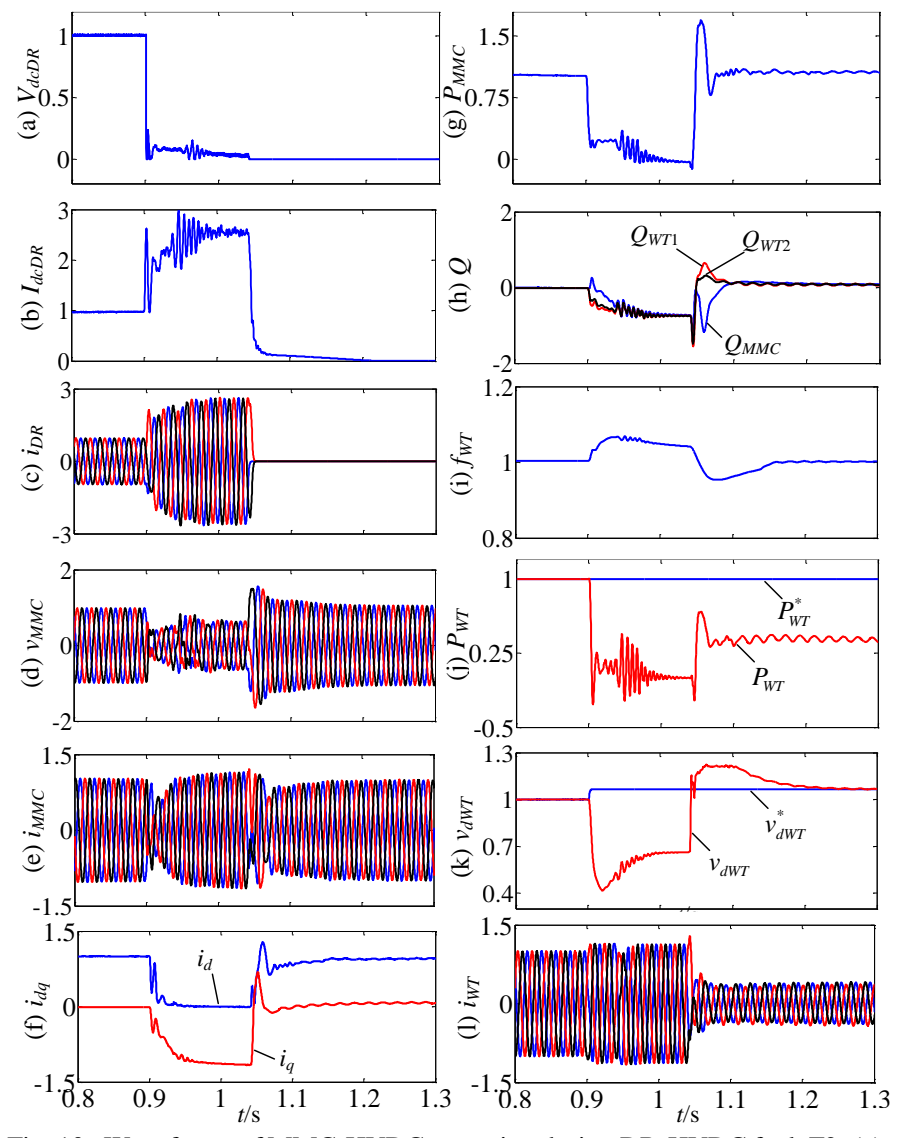

Fig. 10. Waveforms of MMC-HVDC operation during DR-HVDC fault F2: (a) DR DC voltage, (b) DR DC current, (c) breaker $B_{2}$ currents, (d) $\mathrm{MMC}_{1} \mathrm{AC}$ voltages, (e) $\mathrm{MMC}_{1} \mathrm{AC}$ currents, (f) $\mathrm{MMC}_{1} d$ - and $q$-axis currents, (g) $\mathrm{MMC}_{1}$ active power, (h) reactive power, (i) offshore frequency, (j) WT active power, (k) WT $d$-axis voltage, and (1) WT three-phase currents.

\section{Offshore AC Fault (Mode 4)}

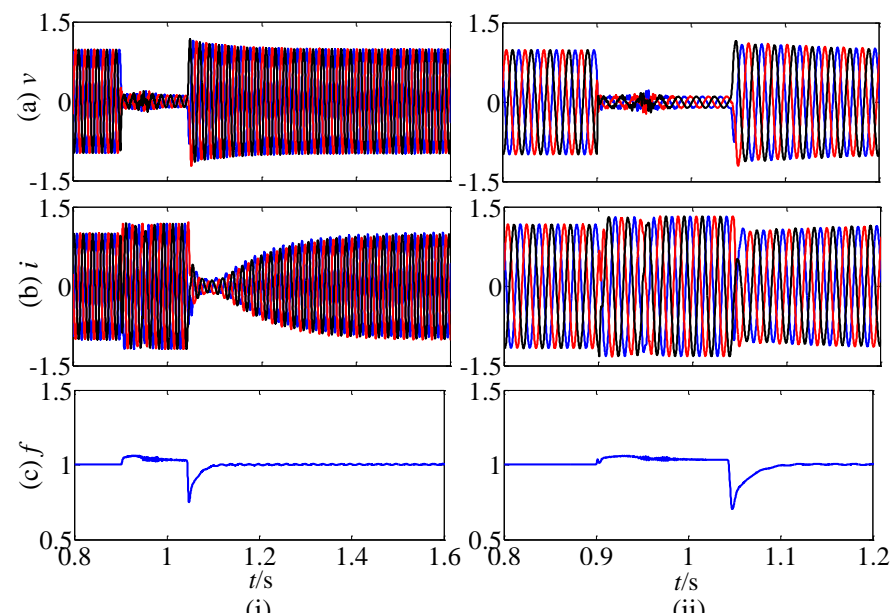

(i)

(ii)

Fig. 11. Waveforms of the independent operation during symmetrical offshore AC fault F3: (a) three-phase voltages, (b) three-phase currents, and (c) frequency of (i) offshore station $\mathrm{MMC}_{1}$ and (ii) WT in OWF 2. 
This paper is a post-print of a paper submitted to and accepted for publication in IEEE Journal of Emerging and Selected Topics in Power Electronics and is subject to Institution of Electrical and Electronic Engineering Copyright. The copy of record is available at IEEE Xplore Digital Library.

As shown in Fig. 11 (a), the offshore AC voltage drops to around 0.1 pu after the solid fault $\mathrm{F} 3$ at the interconnection cable $C a b_{1}$ at $t=0.9 \mathrm{~s}$. Both the active power and voltage control loops saturate and thus set the $d$-axis current reference at its limit. Therefore, both the offshore MMC and WTs operate on current limiting mode to provide fault currents so as to support the offshore network and enable fault detection, as displayed in Fig. 11 (b). At $t=1.04 \mathrm{~s}$, breakers $B_{5}$ and $B_{6}$ open to isolate the fault and then the MMC-HVDC and DR-HVDC systems operate independently. With the developed control strategy, the offshore voltages of the two isolated offshore networks both restore quickly following the fault isolation and can be properly controlled by the MMC and WTs respectively, as seen from Fig. 11 (i) and (ii). The generated power of OWFs 1 and 2 is thus transmitted to onshore via the MMC-HVDC and DRHVDC links, respectively. The offshore frequency experiences disturbance during the fault and gradually recovers after fault isolation, as shown in Fig. 11 (c).

\section{E. Efficiency Evaluation}

To further demonstrate the efficiency superiority of the proposed scheme, the loss evaluations of the tested model with parameters listed in Table I are carried out using the methods as detailed in [44-46]. The semiconductor losses are obtained according to the currents in the simulation and the characteristics of the semiconductor devices [47]. The latter are derived from the datasheet provided by the manufacturer [48, 49] and are stored in a lookup table.

On DR operation, all the generated wind power is transmitted through the DR-HVDC link with the proposed control. When transmitting rated power of $1200 \mathrm{MW}$, the loss of the offshore DR station is $5.8 \mathrm{MW}$, leading to an efficiency of $99.5 \%$, which is higher than the typical efficiency of MMCs (approximately 99\%) [50]. The power losses of the offshore DR (1200 MW) and MMC (800 MW) on parallel operation are 5.8 MW and 7.3 MW, respectively, leading to an overall efficiency of $99.3 \%$. The proposed coordinated control significantly reduces power losses, where the DR-HVDC has the priority to transmit wind power considering the higher efficiency of DRHVDC compared to its MMC counterpart.

\section{CONCLUSION}

DR-HVDC and MMC-HVDC are proposed to transmit offshore wind power where the two DC links operate in parallel with the offshore MMC and DR stations both connected to the offshore wind farm AC network. An enhanced active power control scheme of the offshore MMC station is proposed to improve the power flow distribution between offshore MMC and DR stations during parallel operation. By regulating the offshore voltage, all the wind powers are transmitted via DRHVDC link in low wind conditions while the offshore MMC power is controlled around zero to reduce transmission losses. In high power condition, the offshore MMC controls the offshore $\mathrm{AC}$ voltage at the rated value and shares wind energy transmission with the DR-HVDC link. To deal with the operation of single HVDC link when the other DC link is out of service due to scheduled shutdown, faults etc., coordinated control strategies have been proposed to automatically curtail the generated wind power to avoid potential overload of either the DR-HVDC or MMC-HVDC link. The proposed coordinated control does not rely on communication and can seamlessly handle transitions due to the change of operation conditions and faults. The proposed scheme provides a high efficient solution with flexible operation for integrating large offshore wind farms.

\section{REFERENCES}

[1] M. Amin, A. Rygg, and M. Molinas, "Self-Synchronization of Wind Farm in an MMC-Based HVDC System: A Stability Investigation," IEEE Transactions on Energy Conversion, vol. 32, pp. 458-470, 2017.

[2] J. Lyu, X. Cai, and M. Molinas, "Frequency Domain Stability Analysis of MMC-Based HVdc for Wind Farm Integration," IEEE Journal of Emerging and Selected Topics in Power Electronics, vol. 4, pp. 141-151, 2016.

[3] K. Schönleber, E. Prieto-Araujo, S. Ratés-Palau, and O. Gomis-Bellmunt, "Extended Current Limitation for Unbalanced Faults in MMC\&\#x2013;HVDC\&\#x2013;connected Wind Power Plants," IEEE Transactions on Power Delivery, vol. PP, pp. 1-1, 2017.

[4] L. Zhang, L. Harnefors, and H. P. Nee, "Interconnection of Two Very Weak AC Systems by VSC-HVDC Links Using Power-Synchronization Control," IEEE Transactions on Power Systems, vol. 26, pp. 344-355, 2011.

[5] L. Zhang, L. Harnefors, and H. P. Nee, "Modeling and Control of VSCHVDC Links Connected to Island Systems," IEEE Transactions on Power Systems, vol. 26, pp. 783-793, 2011.

[6] J. Svensson, "Synchronisation methods for grid-connected voltage source converters," IEE Proceedings - Generation, Transmission and Distribution, vol. 148, pp. 229-235, 2001.

[7] W. Wang, Y. Li, Y. Cao, U. Häger, and C. Rehtanz, "Adaptive Droop Control of VSC-MTDC System for Frequency Support and Power Sharing," IEEE Transactions on Power Systems, vol. 33, pp. 1264-1274, 2018.

[8] J. N. Sakamuri, M. Altin, A. D. Hansen, and N. A. Cutululis, "Coordinated frequency control from offshore wind power plants connected to multi terminal DC system considering wind speed variation," IET Renewable Power Generation, vol. 11, pp. 1226-1236, 2017.

[9] O. Kuhn, P. Menke, R. Zurowski, T. Christ, S. Seman, G. Giering, et al., "2nd generation DC grid access for offshore wind farms: HVDC in an AC fashion," CIGRE, Paris, pp. 1-7, 2016.

[10]S. Seman, R. Zurowski, and C. Taratoris, "Interconnection of advanced Type 4 WTGs with Diode Rectifier based HVDC solution and weak AC grids," in Proceedings of the 14th Wind Integration Workshop,Brussels, Belgium, 20th-22nd Oct. , 2015.

[11]T. H. Nguyen, D. C. Lee, and C. K. Kim, "A Series-Connected Topology of a Diode Rectifier and a Voltage-Source Converter for an HVDC Transmission System," IEEE Trans. Power Electron., vol. 29, pp. 15791584, 2014.

[12]R. Blasco-Gimenez, S. A.-. Villalba, J. Rodríguez-D'Derlée, F. Morant, and S. Bernal-Perez, "Distributed Voltage and Frequency Control of Offshore Wind Farms Connected With a Diode-Based HVdc Link," IEEE Transactions on Power Electronics, vol. 25, pp. 3095-3105, 2010.

[13]S. Bernal-Perez, S. Ano-Villalba, R. Blasco-Gimenez, and J. RodriguezD'Derlee, "Efficiency and Fault Ride-Through Performance of a DiodeRectifier- and VSC-Inverter-Based HVDC Link for Offshore Wind Farms," IEEE Transactions on Industrial Electronics, vol. 60, pp. 2401 2409, 2013

[14] R. Blasco-Gimenez, S. Anó-Villalba, J. Rodriguez-D'Derlée, S. BernalPerez, and F. Morant, "Diode-Based HVdc Link for the Connection of Large Offshore Wind Farms," IEEE Transactions on Energy Conversion, vol. 26, pp. 615-626, 2011.

[15]L. Yu, R. Li, and L. Xu, "Distributed PLL-Based Control of Offshore Wind Turbines Connected With Diode-Rectifier-Based HVDC Systems," IEEE Transactions on Power Delivery, vol. 33, pp. 1328-1336, 2018.

[16]R. Li, L. Yu, and L. Xu, "Offshore AC Fault Protection of Diode Rectifier Unit Based HVDC System for Wind Energy Transmission," IEEE Transactions on Industrial Electronics, pp. 1-1, 2018.

[17]R. Zeng, L. Xu, L. Yao, and B. W. Williams, "Design and Operation of a Hybrid Modular Multilevel Converter," Power Electronics, IEEE Transactions on, vol. 30, pp. 1137-1146, 2015.

[18]T. Kawaguchi, T. Sakazaki, T. Isobe, and R. Shimada, "Offshore-WindFarm Configuration Using Diode Rectifier With MERS in Current Link Topology," IEEE Transactions on Industrial Electronics, vol. 60, pp. 29302937, 2013 
This paper is a post-print of a paper submitted to and accepted for publication in IEEE Journal of Emerging and Selected Topics in Power Electronics and is subject to Institution of Electrical and Electronic Engineering Copyright. The copy of record is available at IEEE Xplore Digital Library.

[19]ABB, "HVDC technology for offshore wind is maturing," https://new.abb.com/news/detail/8270/hvdc-technology-for-offshorewind-is-maturing, 2018.

[20] J. L. Rodríguez-Amenedo, S. Arnaltes-Gómez, M. Aragüés-Peñalba, and O. Gomis-Bellmunt, "Control of the Parallel Operation of VSC-HVDC Links Connected to an Offshore Wind Farm," IEEE Transactions on Power Delivery, vol. 34, pp. 32-41, 2019.

[21]"CIGRE Working group B4-55, Technical Brochure 619, HVDC connection of offshore wind power plants," Int. Council Large Electric Syst, (CIGRE), pp. 8-11, 2015.

[22] Y. Chang and X. Cai, "Hybrid Topology of a Diode-Rectifier-based HVDC System for Offshore Wind Farms," IEEE Journal of Emerging and Selected Topics in Power Electronics, pp. 1-1, 2018.

[23] energinet, "KRIEGERS FLAK - COMBINED GRID SOLUTION," https://en.energinet.dk/InfrastructureProjects/Projektliste/KriegersFlakCGS, 2018.

[24] A. Marten, V. Akmatov, T. B. Sørensen, R. Stornowski, D. Westermann, and C. Brosinsky, "Kriegers flak-combined grid solution: coordinated cross-border control of a meshed HVAC/HVDC offshore wind power grid," IET Renewable Power Generation, vol. 12, pp. 1493-1499, 2018.

[25]V. Lescale, P. Holmberg, R. Ottersten, and Y. Hafner, "Parallelling offshore wind farms HVDC ties on offshore side," Proceedings of CIGRE 2012, 2012.

[26] Y. Fu, Y. Wang, and X. Zhang, "Integrated wind turbine controller with virtual inertia and primary frequency responses for grid dynamic frequency support," IET Renewable Power Generation, vol. 11, pp. 1129-1137, 2017.

[27] Y. Wang, M. Yu, and Y. Li, "Self-adaptive inertia control of DC microgrid based on fast predictive converter regulation," IET Renewable Power Generation, vol. 11, pp. 1295-1303, 2017.

[28]X. Hu, J. Liang, D. J. Rogers, and Y. Li, "Power Flow and Power Reduction Control Using Variable Frequency of Offshore AC Grids," IEEE Transactions on Power Systems, vol. 28, pp. 3897-3905, 2013.

[29]M. J. Hossain, H. R. Pota, V. A. Ugrinovskii, and R. A. Ramos, "Simultaneous STATCOM and Pitch Angle Control for Improved LVRT Capability of Fixed-Speed Wind Turbines," IEEE Transactions on Sustainable Energy, vol. 1, pp. 142-151, 2010.

[30]M. Firouzi, G. B. Gharehpetian, and S. B. Mozafari, "Application of UIPC to improve power system stability and LVRT capability of SCIG-based wind farms," IET Generation, Transmission \& Distribution, vol. 11, pp. 2314-2322, 2017.

[31]H. Geng, L. Liu, and R. Li, "Synchronization and Reactive Current Support of PMSG based Wind Farm during Severe Grid Fault," IEEE Transactions on Sustainable Energy, vol. PP, pp. 1-1, 2018.

[32]M. Nasiri and R. Mohammadi, "Peak Current Limitation for Grid Side Inverter by Limited Active Power in PMSG-Based Wind Turbines During Different Grid Faults," IEEE Transactions on Sustainable Energy, vol. 8, pp. 3-12, 2017.

[33]R. Blasco-Gimenez, N. Aparicio, S. Ano-Villalba, and S. Bernal-Perez, "LCC-HVDC Connection of Offshore Wind Farms With Reduced Filter Banks," IEEE Transactions on Industrial Electronics, vol. 60, pp. 23722380, 2013.

[34]J. Renedo, A. García-Cerrada, and L. Rouco, "Reactive-Power Coordination in VSC-HVDC Multi-Terminal Systems for Transient
Stability Improvement," IEEE Transactions on Power Systems, vol. 32, pp. 3758-3767, 2017

[35]G. O. Kalcon, G. P. Adam, O. Anaya-Lara, S. Lo, and K. Uhlen, "SmallSignal Stability Analysis of Multi-Terminal VSC-Based DC Transmission Systems," IEEE Transactions on Power Systems, vol. 27, pp. 1818-1830, 2012.

[36]Y. Li, G. Tang, T. An, H. Pang, P. Wang, J. Yang, et al., "Power Compensation Control for Interconnection of Weak Power Systems by VSC-HVDC," IEEE Transactions on Power Delivery, vol. 32, pp. 19641974, 2017.

[37]S. Mortazavian, M. M. Shabestary, and Y. A. R. I. Mohamed, "Analysis and Dynamic Performance Improvement of Grid-Connected Voltage\&\#8211;Source Converters Under Unbalanced Network Conditions," IEEE Transactions on Power Electronics, vol. 32, pp. 81348149, 2017

[38]O. D. Adeuyi, M. Cheah-Mane, J. Liang, and N. Jenkins, "Fast Frequency Response From Offshore Multiterminal VSC-HVDC Schemes," IEEE Transactions on Power Delivery, vol. 32, pp. 2442-2452, 2017.

[39]R. Li, L. Xu, and D. Guo, "Accelerated switching function model of hybrid MMCs for HVDC system simulation," IET Power Electronics, vol. 10, pp. 2199-2207, 2017.

[40]C. Dong, S. Yang, H. Jia, and P. Wang, "Padé-Based Stability Analysis for a Modular Multilevel Converter Considering the Time Delay in the Digital Control System," IEEE Transactions on Industrial Electronics, vol. 66, pp. 5242-5253, 2019.

[41]C. Wang, L. Xiao, H. Jiang, and T. Cai, "Analysis and Compensation of the System Time Delay in an MMC System," IEEE Transactions on Power Electronics, vol. 33, pp. 9923-9936, 2018.

[42]Y. Jin, J. E. Fletcher, and J. O'Reilly, "Multiterminal DC Wind Farm Collection Grid Internal Fault Analysis and Protection Design," Power Delivery, IEEE Transactions on, vol. 25, pp. 2308-2318, 2010.

[43]Y. Jin, J. E. Fletcher, and J. O'Reilly, "Short-Circuit and Ground Fault Analyses and Location in VSC-Based DC Network Cables," Industrial Electronics, IEEE Transactions on, vol. 59, pp. 3827-3837, 2012.

[44] A. Hassanpoor, S. Norrga, and A. Nami, "Loss evaluation for modular multilevel converters with different switching strategies," in 2015 9th International Conference on Power Electronics and ECCE Asia (ICPEECCE Asia), 2015, pp. 1558-1563.

[45]Q. Tu and Z. Xu, "Power losses evaluation for modular multilevel converter with junction temperature feedback," in Power and Energy Society General Meeting, 2011 IEEE, 2011, pp. 1-7.

[46]S. Bernal-Perez, S. Ano-Villalba, R. Blasco-Gimenez, and J. RodriguezD'Derlee, "Efficiency and Fault Ride-Through Performance of a DiodeRectifier- and VSC-Inverter-Based HVDC Link for Offshore Wind Farms," Industrial Electronics, IEEE Transactions on, vol. 60, pp. 24012409, 2013.

[47] R. Li and J. E. Fletcher, "A novel MMC control scheme to increase the DC voltage in HVDC transmission systems," Electric Power Systems Research, vol. 143, pp. 544-553, 2// 2017.

[48] ABB, 5SDD 50N6000 datasheet, Jun 2017.

[49] ABB, 5SNA 1200G450350 datasheet, Mar 2016.

[50]P. S. Jones and C. C. Davidson, "Calculation of power losses for MMCbased VSC HVDC stations," in 2013 15th European Conference on Power Electronics and Applications (EPE), 2013, pp. 1-10.

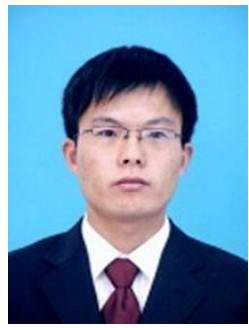

Rui Li received the M.S. and Ph.D degrees in electrical engineering from Harbin Institute of Technology, Harbin, China, in 2008 and 2013, respectively. He is a researcher with University of Strathclyde in Glasgow, UK, since 2013.

His research interests include HVDC transmision system, grid integration of renewable power, power electronic converters, and energy conversion. 


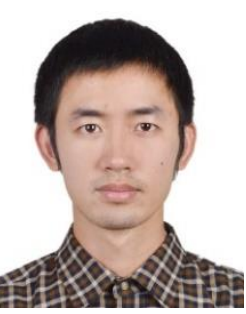

Lujie Yu received the B.S. degree from North China Electric Power University (NCEPU), Baoding, China, in 2012, M.S. degree from NCEPU, Beijing, China, in 2015, Ph.D degree in Electronic \& Electrical Engineering, University of Strathclyde, Glasgow, UK in 2019. Currently, he is a lecturer with School of Electrical and Information Engineering, Tianjin University, Tianjin, China.

His research interests include HVDC transmision system and wind power integration.

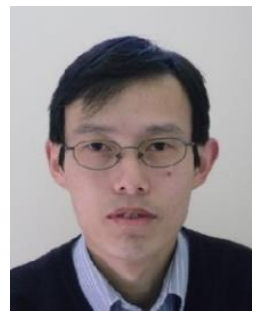

Lie Xu (M'03-SM'06) received the B.Sc. degree in Mechatronics from Zhejiang University, Hangzhou, China, in 1993, and the Ph.D. degree in Electrical Engineering from the University of Sheffield, Sheffield, UK, in 2000.

$\mathrm{He}$ is currently a Professor at the Department of Electronic \& Electrical Engineering, University of Strathclyde, Glasgow, UK. He previously worked in Queen's University of Belfast and ALSTOM T\&D,

Stafford, UK. His research interests include power electronics, wind energy generation and grid integration, and application of power electronics to power systems. He is an Editor of IEEE Transactions on Power Delivery and IEEE Transactions on Energy Conversion.

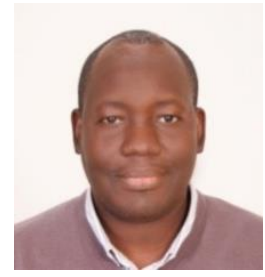

Grain P. Adam (M'12) received the B.Sc. and M.Sc. degrees (Hons.) from Sudan University for Science and Technology, in 1998 and 2002 respectively; and a $\mathrm{PhD}$ in Power Electronics from University of Strathclyde in 2007.

$\mathrm{He}$ is a researcher with University of Strathclyde in Glasgow, UK, since 2008. His research interests are fault tolerant voltage source converters for HVDC applications; modelling and control of HVDC transmission systems and multi-terminal HVDC networks; voltage source converter based FACTS devices; and grid integration issues of renewable energies.

Dr. Adam has authored and co-authored several technical reports, and over 100 journal and conference articles. Dr. Adam has published two books in applications of power electronics in power systems and renewable energy. $\mathrm{He}$ is an active contributor to reviewing process for several IEEE and IET Transactions, Journals and conferences, and a member of IEEE. He is an Associate Editor of Journal of Emerging and Selected Topics in Power Electronics. 